\title{
INFLUÊNCIA DO TIPO DE ORDENHA E DO ARMAZENAMENTO DO LEITE SOBRE A COMPOSIÇÃO QUÍMICA, CONTAGEM DE CÉLULAS SOMÁTICAS E CONTAGEM BACTERIANA TOTAL
}

\section{Influence of the type of milking and storage of milk on the chemical composition, Somatic Cell Count and bacterial count Total}

\author{
Aline Leite Peixoto ${ }^{I}$, Marco Antônio Pereira da Silva ${ }^{{ }^{*}}$, Letícia Aparecida de Morais ${ }^{l}$, \\ Felipe Rocha Silval, Ruthele Moraes do Carmo ${ }^{l}$, Moacir Evandro Lage
}

\section{RESUMO}

A refrigeração do leite e a utilização de ordenhadeiras mecânicas são de suma importância para obtenção de leite de acordo com os padrões de qualidade. Objetivou-se avaliar a influência do tipo de ordenha e do armazenamento sobre a qualidade do leite refrigerado. Foram coletadas 1363 amostras de leite refrigerado armazenado em tanques de expansão individual ou coletivo, de animais ordenhados manualmente e mecanicamente. $\mathrm{O}$ experimento foi realizado em esquema fatorial $2 \times 2$, dois tipos de tanques de expansão (individual e coletivo) e dois tipos de ordenha (manual e mecânica). Empregou-se o delineamento inteiramente ao acaso. Para comparação das médias empregou-se o software Sisvar e o teste de Tukey a 5\% de probabilidade. Os teores de gordura, proteína, lactose e ESD (extrato seco desengordurado), avaliados de acordo com o tipo de ordenha e tipo de armazenamento do leite, foram maiores se comparados aos valores estabelecidos pelo Ministério da Agricultura, Pecuária e Abastecimento. O teor de gordura do leite foi maior em amostras com CCS (contagem de células somáticas) acima de $501 \mathrm{mil} \mathrm{CS} / \mathrm{mL}$, porém os teores de proteína e de extrato seco desengordurado foram maiores em amostras com CCS abaixo de $500 \mathrm{mil} \mathrm{CS} / \mathrm{mL}$. O tipo de ordenha e tipo de armazenamento têm influencia sobre as características de qualidade do leite como teores de gordura, proteína, lactose e CCS. A composição química do leite apresentou-se de acordo com os valores estabelecidos pela legislação brasileira. A CBT (contagem bacteriana total) não variou com o armazenamento e o tipo de ordenha.

Palavras-chave: armazenamento; higiene; proteína; caseína.

1 Instituto Federal de Educação, Ciência e Tecnologia Goiano, Campus Rio Verde, Rodovia Sul Goiana, Km 01, s/n, Zona Rural, 75901-970, Rio Verde, GO, Brasil. E-mail: marcotonyrv@yahoo.com.br

* Autor para correspondência. 


\begin{abstract}
The refrigeration of milk and the usage of mechanical milking are important to obtain milk in accordance with quality standards. In this work we evaluated the influence of the type of milking process and type of storage on the quality of the refrigerated milk. It was obtained 1363 refrigerated milk samples stored in single or collective expansion tanks, from manually or mechanically milked animals. The experiment was carried out in a $2 \times 2$ randomized factorial scheme. Two types of expansion tanks (single and collective) and two types of milking (manual and mechanical). The average comparison test and Tukey test was carried out with $95 \%$ confidence. The levels of fat, protein, lactose and defatted dry extract, were evaluated according to the type of milking and type of milk storage. The values obtained were higher when compared to the values stabilished by the Ministry of Agriculture, Livestock and Food Supply. The level of milk fat was higher in samples with somatic cell count above 501,000 SC/mL. However, the levels of protein and defatted dry extract were higher in samples with somatic cell count below 500,000 $\mathrm{SC} / \mathrm{mL}$. The type of milking and the type of storage have influence on parameters related to milk quality such as levels of fat, protein, lactose and somatic cell count. The milk chemical composition revealed in accordance with the values stabilished by the Brazilian legislation. The total bacterial count did not vary with storage type nor the type of milking.
\end{abstract}

Keywords: storage; hygiene; protein, casein.

\section{INTRODUÇÃO}

$\mathrm{O}$ armazenamento do leite na propriedade leiteira deve ser abaixo de $4{ }^{\circ} \mathrm{C}$, o que, nessas condições, permite a melhor conservação da sua qualidade devido a inibição do crescimento de microrganismos mesófilos. No entanto, tais condições favorecem o crescimento de microrganismos psicrotróficos após 72 horas de armazenamento (BRASIL, 2016).

A presença de bactérias no leite interfere no rendimento, sabor, odor e vida de prateleira, portanto, é de fundamental importância a refrigeração do leite logo após a ordenha e a agilidade no transporte após a coleta até a indústria de laticínios (SILVA et al., 2012).

Para um excelente processo de ordenha existe a necessidade de mão de obra qualificada, entretanto, talvez esse seja um dos principais problemas enfrentados pelos produtores de leite. Desta forma, com o intuito de diminuir despesas e mão de obra, muitos produtores de leite têm utilizado ordenhadeiras mecânicas em substituição a ordenha manual, associado a redução do tempo de trabalho, a praticidade e aumento da lucratividade (MARTINS et al., 2005).

De acordo com Netto et al. (2009), a ordenha manual ou mecânica influencia diretamente na qualidade do leite produzido, ou seja, a ordenha realizada de forma incorreta pode causar lesões no teto do animal e, em consequência, tem-se o aumento considerável da CCS no leite.

A contagem de células somáticas (CCS) é utilizada como um dos principais paramêtros de qualidade nas indústrias de beneficiamento para realizar o pagamento dos produtores em função da qualidade do leite produzido.

Desta forma, objetivou-se avaliar a influência da ordenha manual e mecânica, além do tipo de armazenamento, sobre a qualidade do leite refrigerado. 


\section{MATERIAL E MÉTODOS}

$\mathrm{O}$ estudo foi realizado na região $\mathrm{Su}-$ doeste do estado de Goiás, entre setembro de 2010 a outubro de 2011, em propriedades leiteiras que integravam o programa de coleta a granel de uma empresa de laticínios da região.

Foram coletadas 1363 amostras de leite refrigerado armazenado em tanques de expansão individual $(\mathrm{n}=984)$ e coletivo $(\mathrm{n}=379)$, obtidas de ordenha manual $(n=1091)$ e mecânica $(n=272)$.

As amostras de leite foram coletadas em frascos esterilizados de polietileno contendo conservante bronopol e azidiol para fins de análise da composição química, CCS e CBT. As amostras foram mantidas e transportadas em caixas isotérmicas para o Laboratório de Produtos de Origem Animal (LPOA) do Instituto Federal Goiano - Câmpus Rio Verde, para então serem armazenadas sob refrigeração à temperatura de, aproximadamente, $4{ }^{\circ} \mathrm{C} \mathrm{e}$ em seguida encaminhadas ao Laboratório de Qualidade do Leite do Centro de Pesquisa em Alimentos da Escola de Veterinária e Zootecnia da Universidade Federal de Goiás em Goiânia - GO para avaliação eletrônica conforme descrito abaixo.

Os teores de gordura, proteína, lactose, extrato seco total (EST) e extrato seco desengordurado (ESD) foram determinados por meio da absorção diferencial de ondas infravermelhas pelos componentes do leite, por meio do equipamento Milkoscan 4000 (Foss Electric A/S. Hillerod, Denmark) (IDF, 2000). As amostras de leite foram previamente aquecidas em banho-maria à temperatura de $40{ }^{\circ} \mathrm{C}$, por 15 minutos, para dissolução da gordura e os resultados foram expressos em porcentagem (\%).

A análise de células somáticas (CS), cujo princípio analítico é fundamentado na citometria de fluxo foi realizada em equipamento Fossomatic 5000 Basic (Foss Electric A/S. Hillerod, Denmark), de acordo com a
ISO 13366-2 (IDF, 2006). Antes da análise, as amostras foram aquecidas em banho-maria à temperatura de $40^{\circ} \mathrm{C}$, por 15 minutos, para dissolução da gordura e o resultado foi expresso em $\mathrm{CS} / \mathrm{mL}$.

A contagem bacteriana total (CBT) foi realizada por meio do equipamento Bactoscan FC (Foss Eletric A/S. Hillerod, Denmark), de acordo com a ISO 21187 (IDF, 2004), cujo princípio do método de análise baseiase na citometria de fluxo, ou seja, medição de características das células suspensas em meio fluido. Os resultados foram expressos em UFC/mL.

$\mathrm{O}$ experimento foi realizado em esquema fatorial $2 \times 2$, sendo dois tipos de tanques de expansão (individual e coletivo) e dois tipos de ordenha (manual e mecânica). Empregou-se o delineamento inteiramente ao acaso. Para comparação da qualidade do leite em função da CCS e da CBT empregou-se o software Sisvar (FERREIRA, 2000). Utilizouse o teste de Tukey a $5 \%$ de probabilidade para comparação das médias obtidas.

\section{RESULTADOS E DISCUSSÃO}

Na Tabela 1, são apresentados os valores médios dos componentes químicos, $\mathrm{CCS}$ e CBT do leite refrigerado e coletado em tanques de expansão individuais e coletivos, obtidos por ordenha mecânica ou manual.

Os teores de gordura do leite ordenhado mecanicamente não diferiram significativamente $(\mathrm{p}>0,05)$ em relação ao leite ordenhado manualmente (Tabela 1) e apresentaram-se acima dos padrões legais estabelecidos por Brasil (2016), ou seja, que determina valores mínimos de 3,0\% de gordura. Os valores médios de gordura constatados foram semelhantes aos observados por Souza et al. (2010) que observaram média de 3,63\% de gordura em leite submetido a ordenha manual e mecânica, diferindo também do valor médio constatado por Deresz (2001), que foi de $3,7 \%$ de gordura. 
No leite estocado em tanques individuais observou-se teores de gordura os quais diferiram $(\mathrm{p}<0,05)$ de acordo com o tipo de ordenha, com média de $3,58 \%$ de gordura para o leite ordenhado mecanicamente e $3,65 \%$ de gordura para o leite ordenhado manualmente. Entretanto, os teores de gordura do leite estocado em tanques coletivos não diferiram $(p>0,05)$ em função do tipo de ordenha.

O maior teor de gordura do leite obtido por ordenha manual pode ser associado ao método de amostragem ou a variações inerentes à raça do animal, alimentação do rebanho ou estádio da lactação, ressaltando-se que a gordura é o componente que apresenta com maior amplitude de variação dentre os compostos químicos do leite.

Os teores de proteína do leite ordenhado mecanicamente não diferiram $(\mathrm{p}>0,05) \mathrm{em}$ relação ao tipo de armazenamento, com 3,24\% para o leite estocado em tanques de expan- são coletivos e $3,23 \%$ para o leite estocado em tanques individuais (Tabela 1). O leite ordenhado manualmente também apresentou teores de proteína que não diferiram ( $\mathrm{p}>$ $0,05)$ em relação ao tipo de armazenamento, com valores de 3,29\% de proteína para o leite estocado em tanques individuais e leite estocado em tanques coletivos. Os valores de proteína observados foram superiores aos teores relatados por Netto et al. (2009) que, ao compararem a qualidade do leite em ordenha manual e mecânica, verificaram 3,00\% de proteína no leite ordenhado mecanicamente e de $3,20 \%$ de proteína no leite ordenhado manualmente.

Os teores de proteína do leite estocado em tanques individuais, diferiram $(\mathrm{p}<0,05)$ em função do tipo de armazenamento, com valores médios de $3,23 \%$ de proteína para o leite ordenhado mecanicamente e 3,29\% para o leite ordenhado manualmente. Os teores

Tabela 1 - Valores médios dos componentes químicos avaliados, contagem de células somáticas (CCS) e contagem bacteriana total (CBT) do leite refrigerado coletado em de tanques de expansão individuais e em tanques coletivos, submetidos à ordenha mecânica e manual

\begin{tabular}{c|c|c|c}
\hline \multirow{2}{*}{ Componente } & Tipo de & \multicolumn{2}{|c}{ Tipo de Armazenamento } \\
\cline { 3 - 4 } & Ordenha & Individual & Coletivo \\
\hline \multirow{2}{*}{ Gordura (\%) } & Mecânica & $3,58^{\mathrm{Ab}}$ & $3,61^{\mathrm{Aa}}$ \\
& Manual & $3,65^{\mathrm{Aa}}$ & $3,68^{\mathrm{Aa}}$ \\
\hline \multirow{2}{*}{ Proteína (\%) } & Mecânica & $3,23^{\mathrm{Ab}}$ & $3,24^{\mathrm{Aa}}$ \\
& Manual & $3,29^{\mathrm{Aa}}$ & $3,29^{\mathrm{Aa}}$ \\
\hline Lactose (\%) & Mecânica & $4,44^{\mathrm{Ab}}$ & $4,45^{\mathrm{Aa}}$ \\
\hline ESD (\%) & Manual & $4,49^{\mathrm{Aa}}$ & $4,52^{\mathrm{Aa}}$ \\
\hline CCS (x 1000 CS/mL) & Mecânica & $8,64^{\mathrm{Ab}}$ & $8,68^{\mathrm{Aa}}$ \\
& Manual & $8,78^{\mathrm{Aa}}$ & $8,76^{\mathrm{Aa}}$ \\
\hline CBT (x 1000 UFC/mL) & Mecânica & $985^{\mathrm{Aa}}$ & $478^{\mathrm{Ba}}$ \\
& Manual & $576^{\mathrm{Ab}}$ & $582^{\mathrm{Aa}}$ \\
\hline
\end{tabular}

* Letras maiúsculas distintas na linha diferem entre si a 5\% de probabilidade. ** Letras minúsculas distintas na coluna diferem entre si a $5 \%$ de probabilidade. 
de proteína no leite estocado em tanques coletivos não diferiram ( $p>0,05)$ em função do tipo de ordenha. A variação nos teores de proteína do leite pode ser relacionada a dieta fornecida aos animais.

O valor minímo de proteína exigido pelas indústrias de beneficiamento por meio da legislação brasileira é de $2,9 \%$, contudo, os valores observados foram superiores, com variação entre 3,23\% a 3,29\%. A variação do teor de proteína do leite é menor quando comparada a variação do teor de gordura (BLOCK, 2000) o que, segundo Dürr (2002), pode ser associado a dieta dos animais.

O teor de lactose em leite ordenhado mecanicamente não diferiu $(\mathrm{p}>0,05) \mathrm{em}$ função do tipo de armazenamento. Na estocagem em tanques de expansão coletivos o teor de lactose foi de $4,45 \%$, enquanto no leite estocado em tanques individuais o valor médio foi de $4,44 \%$. No leite ordenhado manualmente também não foi constatada diferença significativa $(p>0,05)$ do teor de lactose em relação ao tipo de armazenamento. Esse resultado é semelhante ao observado por Ribeiro Neto et al. (2012) que observaram teor médio de lactose de $4,41 \%$ em leite estocado em tanques de expansão na região nordeste do Brasil.

Os teores de lactose do leite estocado em tanques individuais diferiram $(\mathrm{p}<0,05)$ em função do tipo de ordenha, com média de $4,44 \%$ de lactose para o leite ordenhado mecanicamente e de $4,49 \%$ para o leite ordenhado manualmente. O leite estocado em tanques coletivos apresentou teores de lactose que não diferiram $(\mathrm{p}>0,05)$ em função do tipo de ordenha.

O teor de lactose do leite ordenhado mecanicamente foi inferior ao teor de lactose do leite ordenhado manualmente, resultado que pode ser explicado pelo fato de que, leite de animais com alta CCS está associado a ocorrência de inflamação da glândula mamária, a qual provoca a redução da síntese de lactose nos alvéolos, além do aumento da permeabilidade dos capilares, assim parte considerável da lactose do leite é perdida para a corrente sanguínea (MACHADO et al., 2006).

O ESD do leite ordenhado mecanicamente não diferiu $(\mathrm{p}>0,05)$ em relação ao tipo de armazenamento. Em tanques coletivos o valor médio de ESD do leite foi de $8,68 \%$ e, em tanques individuais, o leite apresentou valor médio de 8,64\%. O ESD leite ordenhado manualmente não diferiu ( $p>0,05)$ em relação ao tipo de armazenamento, com valor médio de $8,76 \%$ de ESD em leite armazenado em tanques coletivos e $8,78 \%$ em leite estocado em tanques individuais. Valores inferiores de ESD, foram observados por Ribeiro Neto et al. (2012), com média de $8,44 \%$ de ESD no leite refrigerado da região nordeste. Magalhães et al. (2004), relataram em pesquisa valores superiores de ESD, com variação de $9,22 \%$ a 9,41\%.

Houve diferença $(\mathrm{p}<0,05)$ entre o ESD de leite estocado em tanques individuais em função do tipo de ordenha. O leite obtido por ordenha manual apresentou médias superiores de ESD quando comparado ao leite obtido por ordenha mecânica, com valores médios de $8,78 \%$ e $8,64 \%$, respectivamente. O ESD do leite estocado em tanques de produtores coletivos não diferiu significativamente $(\mathrm{p}>$ 0,05) em função do tipo de ordenha.

A variação do ESD foi influenciada pela variação nos teores de proteína e lactose, tanto para o leite obtido por ordenha manual quanto para leite obtido por ordenha mecânica. Os resultados desse estudo diferem dos observados por Reis et al. (2007) que ao avaliarem procedimentos de coleta de leite cru individual e a relação com a composição físico-química e a CCS, constataram $8,25 \%$ de ESD para o leite obtido por ordenha mecânica e de $8,59 \%$ para o leite ordenhado manualmente.

A variação do ESD do leite de animais ordenhados mecanicamente em relação ao leite de animais ordenhados manualmente, 
é relacionada, principalmente à raça dos animais, em que produtores que dispõem de ordenhadeiras mecânica utilizam animais especialmente da raça holandesa que, por sua vez, produzem menores teores de sólidos quando comparado as demais raças.

Leite obtido por ordenha mecânica apresentou valores de CCS diferentes $(\mathrm{p}<$ $0,05)$ em relação ao tipo de armazenamento, com CCS de $985 \mathrm{mil} \mathrm{CS} / \mathrm{mL}$ para o leite estocado em tanques individuais e de 478 mil CS/mL para o leite estocado em tanques coletivos. A CCS do leite ordenhado obtido por ordenha manual não diferiu $(p>0,05) \mathrm{em}$ relação ao tipo de armazenamento. O leite estocado em tanques individuais apresentou CCS de $576 \mathrm{mil} \mathrm{CS} / \mathrm{mL}$ e o leite estocado em tanques coletivos apresentou CCS de 582 mil CS/mL.

Para o leite estocado em tanques coletivos os valores de CCS não diferiram $(p>0,05)$ em função do tipo de ordenha. A variação da CCS do leite é relacionada a falta de higiene na obtenção do leite durante os procedimentos de ordenha, elevando os níveis de mastite no rebanho e consequentemente o aumento na CCS.

Um dos principais indicadores de qualidade de leite empregados pelos laticínios é a CCS, análise que permite evidenciar, principalmente, a incidência de mastite no rebanho. Essa doença afeta diretamente a glândula mamária com consequente redução da produção de leite. A CCS apresenta correlação negativa com a produção de leite e positiva com o teor de gordura e de proteína (CUNHA et al., 2008).

Essa correlação pode ser explicada pelo fato de que o aumento da CCS decorrente de inflamação da glândula mamária, provoca o aumento da vascularização e o aumento da permeabilidade dos capilares. Desta forma, parte da proteína sanguinea é perdida para o interior da glândula mamária (MACHADO et al., 2006).

Os valores de CBT do leite obtido de ordenha mecânica diferiram $(\mathrm{p}<0,05)$ em relação do tipo de armazenamento. O leite obtido por ordenha mecânica e estocado em tanques individuais apresentou maior valor de CBT do que o leite obtido por ordenha mecânica e estocado em tanques coletivos, com valores médios de $1.505 \mathrm{mil} \mathrm{UFC/mL} \mathrm{e}$ $854 \mathrm{mil} \mathrm{UFC/mL}$, respectivamente.

De acordo com a legislação brasileira, os resultados da CBT do leite obtido por ordenha manual e mecânica não atenderam ao padrão mínimo que é de até $300 \mathrm{mil} \mathrm{UFC} / \mathrm{mL}$. A CBT é uma análise indicativa das condições de higiene, antes, durante e após a ordenha. A presença da microbiota contaminante pode afetar diretamente a qualidade e inocuidade do leite e derivados, como riscos à saúde do consumidor.

O leite estocado em tanques individuais apresentou valores de CBT que diferentes $(\mathrm{p}<0,05)$ de acordo com o tipo de ordenha. Nos tanques individuais obtidos por ordenha mecânica, os valores de CBT foram superiores comparado aos valores constatados em leite obtido por meio de ordenha manual. A utilização de leite de baixa qualidade influencia negativamente sobre a qualidade dos produtos derivados como redução de rendimento, alterações de sabor, odor e redução da vida útil.

$\mathrm{Na}$ Tabela 2, são apresentados os valores médios e coeficientes de variação da gordura, proteína, ESD e CBT do leite refrigerado em função da CCS abaixo de $500 \mathrm{mil} \mathrm{CS} / \mathrm{mL}$ e acima de $501 \mathrm{mil} \mathrm{CS} / \mathrm{mL}$.

Observou-se para as amostras de leite refrigerado com CCS abaixo de $500 \mathrm{mil}$ $\mathrm{CS} / \mathrm{mL}$ menor teor de gordura comparado as amostras com contagens acima de $501 \mathrm{mil}$ $\mathrm{CS} / \mathrm{mL}$ (Tabela 2). Machado et al. (2006) ao analisarem a composição do leite armazenado em tanques de rebanhos brasileiros distribuídos segundo sua contagem de células somáticas também observou que a porcentagem de gordura do leite aumentava de acordo com o aumento da CCS. 
Os teores médios de proteína e ESD nas amostras de leite com CCS inferior a 500 $\mathrm{mil} \mathrm{CS} / \mathrm{mL}$ foram menores em relação às amostras com CCS acima de $501 \mathrm{mil} \mathrm{CS} / \mathrm{mL}$. A CBT das amostras de leite refrigerado não foi alterada $(p>0,05)$ em função da concentração de CCS.

De acordo com Bozo et al. (2013) é possível reduzir a CBT de rebanhos leiteiros por meio da implementação de procedimentos adequados de higienização dos equipamentos de ordenha. Entretanto, neste caso, não há redução das CCS, situação que demonstra que são variáveis independentes já que a CBT é uma medida direta de contaminação do leite e a CCS é uma medida indireta de inflamação da glândula mamária.

$\mathrm{Na}$ Tabela 3, estão dispostos os valores médios e coeficientes de variação da gordura, proteína, ESD e contagem de células somáticas (CCS) do leite refrigerado em função da contagem bacteriana total (CBT) inferior a 300 mil UFC/mL e superior a $301 \mathrm{mil} \mathrm{UFC/mL}$.

A porcentagem de gordura não foi influenciada $(\mathrm{p}>0,05)$ pela CBT nas amostras de leite cru refrigerado.

O ESD e os teores de proteína apresentaram redução com o aumento da CBT, resultado que pode ser relacionado à presen ça de bactérias psicotróficas que, em tem-

Tabela 2 - Valores médios e coeficiente de variação (CV) da gordura, proteína, extrato seco desengordurado (ESD) e contagem bacteriana total (CBT) do leite refrigerado em função da contagem de células somáticas (CCS) abaixo de $500 \mathrm{mil} \mathrm{CS} / \mathrm{mL}$ e acima de $501 \mathrm{mil} \mathrm{CS} / \mathrm{mL}$ na região sudoeste de Goiás

\begin{tabular}{cccc}
\hline \multirow{2}{*}{ Componente } & \multicolumn{2}{c}{ CCS } & \multirow{2}{*}{ CV (\%) } \\
\cline { 2 - 3 } & Abaixo de $500 \mathrm{mil} \mathrm{CS} / \mathrm{mL}$ & Acima de $501 \mathrm{mil} \mathrm{CS} / \mathrm{mL}$ & 11,58 \\
\hline Gordura (\%) & $3,62^{\mathrm{b}}$ & $3,67^{\mathrm{a}}$ & 6,59 \\
Proteína (\%) & $3,31^{\mathrm{a}}$ & $3,25^{\mathrm{b}}$ & 3,59 \\
ESD $(\%)$ & $8,84^{\mathrm{a}}$ & $8,66^{\mathrm{b}}$ & 205,12 \\
CBT $(\mathrm{UFC} / \mathrm{mL})$ & $1.116 .312^{\mathrm{a}}$ & $1.237 .936^{\mathrm{a}}$ & \\
\hline
\end{tabular}

Letras maiúsculas distintas na linha diferem significativamente entre si ao nível de 5\% de significância.

Tabela 3 - Valores médios e coeficiente de variação (CV) da gordura, proteína, extrato seco desengordurado (ESD) e contagem de células somáticas (CCS) do leite refrigerado em função da contagem bacteriana total (CBT) abaixo de $300 \mathrm{mil} \mathrm{UFC/mL} \mathrm{e} \mathrm{acima} \mathrm{de} 301 \mathrm{mil} \mathrm{UFC/mL}$

\begin{tabular}{cccc}
\hline \multirow{2}{*}{ Componente } & \multicolumn{2}{c}{$\mathrm{CBT}$} & \multirow{2}{*}{ CV (\%) } \\
\cline { 2 - 3 } & Abaixo de $300 \mathrm{mil} \mathrm{CS} / \mathrm{mL}$ & Acima de $301 \mathrm{mil} \mathrm{CS} / \mathrm{mL}$ & 11,58 \\
\hline Gordura (\%) & $3,67^{\mathrm{a}}$ & $3,62^{\mathrm{a}}$ & 6,63 \\
Proteína (\%) & $3,29^{\mathrm{a}}$ & $3,27^{\mathrm{b}}$ & 3,71 \\
ESD $(\%)$ & $8,79^{\mathrm{a}}$ & $8,72^{\mathrm{b}}$ & 103,95 \\
CCS $(\mathrm{CS} / \mathrm{mL})$ & $571.043^{\mathrm{b}}$ & $745.842^{\mathrm{a}}$ & \\
\hline
\end{tabular}

Letras maiúsculas distintas na linha diferem significativamente entre si ao nível de 5\% de significância. 
peraturas de refrigeração, produzem altas concentrações de enzimas lipolíticas e proteolíticas termorresistentes responsáveis pela degradação da proteína e da gordura com consequentes alterações físicas do leite (BISHOP, 1998).

As amostras de leite refrigerado que possuíam CBT abaixo de $300 \mathrm{mil} \mathrm{UFC} / \mathrm{mL}$ apresentaram menor contagem de $\mathrm{CCS} / \mathrm{mL}$ em relação às amostras que apresentaram

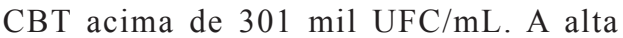
CCS em leite refrigerado pode influenciar significamente o rendimento de produtos lácteos, como queijos e ocasionar maior perda de proteína no soro (SILVA et al., 2012).

A qualidade do leite está relacionada com fatores como higiene durante o processo de obtenção, agilidade no transporte, raça do animal, manejo nutricional e estágio de lactação (CAVALETTI et al., 2011).

\section{CONCLUSÕES}

O tipo de armazenamento e o tipo de ordenha exercem influência sobre os teores de gordura, proteína, lactose, ESD e CCS do leite. Os resultados para composição química do leite do presente estudo estão de acordo com os valores estabelecidos pela legislação brasileira. A CBT não variou de acordo com o armazenamento e o tipo de ordenha.

Deve-se levar em consideração que a implantação de novas tecnologias demanda mão de obra qualificada para que possam ser alcançados padrões de qualidade de leite que atendam os padrões exigidos pela legislação.

A implementação de ordenhadeiras mecânicas e de tanques isotérmicos representaram um avanço considerável para a cadeia produtiva de leite, com a possibilidade de obter leite de melhor qualidade. Entretanto, ainda são poucas as indústrias de laticínios que participam do programa de pagamento por qualidade, no sentido de incentivar o produtor a obter matéria-prima de alta qualidade.

\section{AGRADECIMENTOS}

A Fundação de Amparo à Pesquisa do Estado de Goiás (Fapeg), Coordenação de Aperfeiçoamento de Pessoal de Nível Superior (CAPES) e Conselho Nacional de Desenvolvimento Científico e Tecnológico $(\mathrm{CNPq})$ pelo apoio financeiro a realização da pesquisa.

\section{REFERÊNCIAS}

BISHOP, J. R.; WHITE, C. H. Estimation of potencial shelf-life of pasteurized fluid milk utilizing bacterial numbers and metabolites. Journal Food Protection, v. 48, n. 8, p. 663$667,1985$.

BLOCK, E. Nutrição de vacas leiteiras e com posição do leite. In: ENCONTRO ANUAL DO CONSELHO BRASILEIRO DE QUALIDADE DO LEITE, 2000, Curitiba, PR. Anais... Curitiba: Centro Integrado dos empresários e trabalhadores das Indústrias do Paraná CIETEP/FIEP, 2000. p. 85-88.

BOZO, G. A. et al. Adequação da contagem de células somáticas e da contagem bacteriana total em leite cru refrigerado aos parâmetros da legislação. Arquivo Brasileiro Medicina Veterinária e Zootecnia, v. 65, n. 2, p. 589594, 2013.

BRASIL. Ministério da Agricultura, Pecuária e Abastecimento. Instrução Normativa $\mathrm{n}^{\circ}$ 62, de 29 de dezembro de 2011. Aprova o Regulamento Técnico de Produção, Identidade e Qualidade do Leite tipo A, o Regulamento Técnico de Identidade e Qualidade de Leite Cru Refrigerado, o Regulamento Técnico de Identidade e Qualidade de Leite Pasteurizado e o Regulamento Técnico da Coleta de Leite Cru Refrigerado e seu Transporte a Granel, em conformidade com os Anexos desta Instrução Normativa. Diário Oficial da República Federativa do Brasil, Brasília, 30 dez. 2011. Seção 1, p. 6. 
CAVAlETTI, L. C. et al. Rastreamento de fontes da contaminação microbiológica do leite cru durante a ordenha em propriedades leiteiras do Agreste Pernambucano. Semina: Ciências Agrárias, v. 32, n. 1, p. 267-276, 2011.

CUNHA, R. P. L. et al. Mastite subclínica e relação da contagem de células somáticas com número de lactações, produção e composição química do leite em vacas da raça Holandesa. Arquivo Brasileiro Medicina Veterinária e Zootecnia, v. 60, n. 1, p. 19-24, 2008.

DERESZ, F. Influência do período de descanso da pastagem de capim-elefante na produção de leite de vacas mestiças Holandês x Zebu. Revista Brasileira de Zootecnia, v. 30, n. 2, p. 461-469, 2001.

DÜRR, J. W. Atualização em pastagem e produção animal - ruminantes. In:

Curso de extensão - Universidade de Passo Fundo. Passo Fundo: Universitária, 2002. cap. 11, p. 33-58.

FERREIRA, D. F. Sistema de análise estatística para dados balanceados (SISVAR). Lavras: UFLA/DEX, 2000.

INTERNATIONAL DAIRY FEDERATION (IDF) $141 \mathrm{C}$ : Determination of milkfat, protein and lactose content - Guidance on the operation of mid-infrared instruments. Brussels: FIL/IDF, 2000. 15p.

INTERNATIONAL DAIRY FEDERATION (IDF) 196: Milk - Quantitative determination of bacteriological quality - Guidance for establishing and verifying a conversion relationship between routine method results and anchor method results. Brussels: FIL/ IDF, 2004. $13 \mathrm{p}$.

ISO 13366-2/INTERNATIONAL DAIRY FEDERATION (IDF) 148-2 - Milk - Enumeration of somatic cells - Part 2: Guidance on the operation of fluoro-opto-electronic counters. Brussels: FIL/IDF, 2006. 15 p.
MACHADO, P. F. et al. Composição do leite de tanques de rebanhos brasileiros distribuídos segundo sua contagem de células somáticas. Revista Brasileira de Zootecnia, v. 29, n. 6, p. 95, 2006.

MAGALHÃES, A. L. R. et al. Cana-deaçúcar em substituição à silagem de milho em dietas para vacas em lactação: desempenho e viabilidade econômica. Revista Brasileira de Zootecnia, v. 33, n. 5, p. 1292-1302, 2004.

MARTINS, M. L. et al. Detection of the apr gene in proteolytic psychrotrophic bactéria isolated from refrigerated raw milk. Internanational Journal of Food Microbiology, v. 102, p. 203-211, 2005.

NETTO, A. S. et al. Estudo comparativo da qualidade do leite em ordenha manual e mecânica. Revista do Instituto de Ciências de Saúde, v. 27, n. 9, p. 345-349, 2009.

REIS, G. L. et al. Procedimentos de coleta de leite cru individual e sua relação com a composição físico-química e a contagem de células somáticas. Ciência Rural, v. 37, n. 4, p. 1134-1138, 2007.

RIBEIRO NETO, A. C. et al. Qualidade do leite cru refrigerado sob inspeção federal na região Nordeste. Arquivo Brasileiro de Medicina Veterinária e Zootecnia, v. 64, n. 5, p. 13431351, 2012.

SILVA, N. M. A. et al. Influence of somatic cell count and total bacterial counts of raw milk in cheese yield using small-scale methodology. Arquivos Brasileiros de Medicina Veterinária e Zootecnia, v. 64, n. 5, p. 1367 $1372,2012$.

SOUZA, R. et al. Produção e qualidade do leite de vacas da raça Holandesa em função da estação do ano e ordem de parto. Revista Brasileira de Saúde e Produção Animal, v. 11, n. 2 , p. 484-495, 2010. 